\title{
ЦИФРОВИЗАЦИЯ В ОБРАЗОВАНИИ: ПОЛОЖИТЕЛЬНЫЕ И ОТРИЦАТЕЛЬНЫЕ СТОРОНЫ
}

\author{
Чомаева Мариям Мухтаровна \\ МКОУ «СОШ №7 им. Б. Д. Узденова с. Учкекен»
}

Аннотация. Цифровизация сегодня охватывает почти все сферы нашей повседневной жизни. С внедрением новых технологий изменилась и система образования. После компьютеризации и информатизации образования пришло время его цифровой трансформации. Суть цифровой трансформации образования в том, чтобы эффективно и гибко применить новейшие технологии в системе образования. Цифровизация и перевод многих процессов в онлайн позволили реализовать образовательные процессы по-новому, организовав передачу и распространение знаний более эффективно как для передающего, так и получающего. Многие ошибочно думают, что цифровизация - система оценивания как педагогов, так и обучающихся. Но это не так, цифровизация система, которая позволяет провести масштабную диагностику. Учет и анализ данных помогает понять, каких успехов добился ученик, узнать, по какому предмету ему сложно освоить материал, помочь ему и в итоге повысить уровень его знаний. Суть цифровой трансформации в том, чтобы эффективно и гибко применять новейшие технологии. Однако учёные бьют тревогу, что полная цифровизация образования негативно скажется как на образовании детей, так и на их здоровье. Роль педагога не смогут заменить ничем, цифровые технологии должны иметь только сопутствующий характер. Ведь живое общение педагога и обучающегося,- это та ценность, которую нельзя потерять.

Ключевые слова: цифровизация образования; цифровая трансформация образования; цифровые технологии в образовании; электронное обучение; дистанционное обучение; онлайн-обучение; подготовка педагогических кадров.

\section{DIGITALIZATION IN EDUCATION: POSITIVE AND NEGATIVE SIDES}

\section{Chomaeva Mariam Mukhtarovna}

Annotation. Digitalization today covers almost all areas of our daily life. With the introduction of new technologies, the education system has also changed. After 
the computerization and informatization of education, the time has come for its digital transformation. The essence of digital transformation of education is to effectively and flexibly apply the latest technologies in the education system. Digitalization and the transfer of many processes to online have made it possible to implement educational processes in a new way, organizing the transfer and dissemination of knowledge more effectively for both the transmitting and receiving. Many people mistakenly think that digitalization is a system for evaluating both teachers and students. But this is not so, digitalization is a system that allows for large-scale diagnostics. Accounting and data analysis helps to understand what successes the student has achieved, to find out in what subject it is difficult for him to master the material, to help him and, as a result, to increase his level of knowledge. The essence of digital transformation is to apply the latest technologies efficiently and flexibly. However, scientists are sounding the alarm that the complete digitalization of education will negatively affect both the education of children and their health. The role of a teacher cannot be replaced by anything, digital technologies should only be of a concomitant nature. After all, live communication between a teacher and a student is a value that cannot be lost!

Keywords: digitalization of education; digital transformation of education; digital technologies in education; e-learning; distance learning; online learning; teacher training.

Сейчас практически невозможно найти человека, который был бы связан только с практическим формальным образованием. Всех в 2020 году затронуло электронное дистанционное обучение, связанно это было с неожиданной пандемией. По данным ООН, от пандемии пострадало 94\% от общего числа студентов, что составляет почти 1,6 миллиарда учащихся в 190 странах. Хотя закрытие школ и университетов особенно сильно ударило по традиционным системам образования, они все же смогли противостоять шторму с помощью инструментов цифрового обучения. Фактически ограничения пандемии резко увеличили спрос на цифровые образовательные технологии в целом [1].

В процесс электронного обучения были вовлечены все обучающиеся и педагоги образовательных учреждений, независимо от их желания. Даже те, кто с этими технологиями совершенно не был знаком. Цифровизация образования предполагает переход (трансформацию) от традиционного образования к цифровому. В связи с чем происходит внедрение новых технологий в образовательный процесс для улучшения качества образования, повышения 
доступности и открытости сферы образования для всех участников образовательного процесса.

Цифровая трансформация образования требует определённых знаний, умений и навыков для взаимодействия с цифровой седой. Эффективность данного процесса зависит от менталитета каждого субъекта, понимания возможностей цифровых образовательных технологий, а также риска, связанного с ними. Данный процесс предполагает, что обучающиеся будут выходить на индивидуальные траектории образования, а педагоги будут проходить непрерывное онлайн-обучение.

Как и любое нововведение, процесс цифровизации образования проходит через призму критики. Мнения в отношении цифровизации образования разнятся.

Положительные стороны. Одной из важнейших задач в образовании, которую удалось решить цифровизации, - это свободный доступ к информации. Теперь нет необходимости тратить много времени на поиск данных. Также данный процесс помогает в значительной мере ускорить процесс обучения. Обучающимся больше не нужно физически никуда идти. Они в режиме реального времени могут иметь свободный доступ к любым тренажёрам, коллекциям видео-уроков, моделям-имитаторам, библиотечным ресурсам мира, учебным материалам лучших преподавателей. Также данный процесс очень помогает детям с ограниченными возможностями.

В связи с цифровизацией образования, в большинстве школ открылись электронные дневники, электронные журналы. Теперь дети не могут скрыть от родителей свои оценки, данные о посещаемости уроков, также родители имеют возможность задавать вопросы, писать комментарии, узнавать новости, активно участвовать в жизни школы и ребёнка. И для этого совсем не нужно куда-то ехать.

Электронные журналы учащихся освобождают учителей от рутиной работы по обработке данных и заполнению отчётов вручную. Педагоги начали осваивать новый взгляд на структуру урока, новые формы передачи знаний. Цифровизацию в образовании нужно глубоко изучить и прочувствовать, только потом педагог имеет право включить её в свою работу. Можем сделать вывод, что по мере развития новых технологий, широко внедряемых в образовательные программы, педагоги постепенно начинают переосмысливать и методики преподавания предмета. 
Сейчас наука развивается с большой скоростью, каждый день появляются новые структуры. Цифровизация обучения поможет обучающимся лучше ориентироваться в информационном мире в будущем.

Отрицательные стороны. Мы понимаем, что цифровизация образования предполагает длительное использование всевозможных гаджетов (смартфонов, компьютеров, планшетов...). В связи с этим у обучающихся повышается эмоциональная, умственная, зрительная нагрузка. Происходит ухудшение внимания, головные боли, проблемы со зрением. Дети любят много времени проводить за экраном, что приводит к ожирению, диабету, недоразвитости социальных навыков, депрессии и к другим психологическим состояниям. Восприятие информации у детей становится всё более поверхностным. Подобное мышление приводит к тому, что мир воспринимается не целостно, а маленькими осколками без логической связи, в результате ребёнок не имеет возможность осмыслить какую-либо тему, привыкает к постоянной смене сообщений и требует новых. Самая большая тревога учителей заключается в том, что дети не понимают смысла прочитанного. Гаджеты стали цифровым наркотиком. Они так сильно возбуждают мозговую деятельность, что в организме повышается уровень «допамина», участвующего в формировании зависимости. Такое же действие на организм человека оказывают алкоголь и наркотики. В отличие от взрослых, дети не умеют контролировать свои импульсы и желания. Цифровые технологии дают возможность не ограничивать себя в желаниях, в связи с чем формируется зависимость. Это очень сильно беспокоит родителей учащихся.

В статье А. Афанасьева перечислены и прокомментированы угрозы здоровью и развитию ребенка, которые очевидны специалистам в образовании и медицине, но умалчиваются авторами проекта: цифровое слабоумие (утрата умственных способностей), утрата навыков письма, утрата способностей воспринимать большие тексты, проблемы с речевым развитием у детей, проблемы со зрением, снижение социальных навыков, экранная зависимость и др. [2].

Далее следует согласиться с мнением, высказанным в работе Е. А. Дьяковой и Г. Г. Сечкаревой, что «Дистанционное обучение - скорее вынужденный вариант. Для педагогического образования возможен только смешанный вариант, т. к. работе с людьми (детьми) невозможно научиться дистанционно, даже с помощью телекоммуникационных сетей» [3]. 
Абсолютный контроль. Это относится к обучающимся, педагогам и родителям. На каждого человека заводится личное дело, собирается подробная информация о семье. Это приведет к тотальному контролю общества.

Функция педагогов. После цифровизации понятие педагога будет полностью изменено. Профессионалов заменят роботы и виртуальные системы. Люди лишатся работы. [4, с. 50].

В заключении хотим сказать, что согласны с мнением, высказанным в интервью c С.А. Бешенковым - заведующим лабораторией дидактики информатики Института содержания и методов обучения Российской академии образования: «Знание - это системное, глубинное представление о мире, настолько глубинное, что становится возможным предсказывать новые факты. Можно ли такое знание получить только с помощью „цифры“? Вряд ли. Нужен живой учитель, наставник, а „цифра““ будет ему в помощь» [5].

\section{Список литературы}

1. Хамитов Р. М. ЦИФРОВИЗАЦИЯ ОБРАЗОВАНИЯ И ЕЕ АСПЕКТЫ // Современные проблемы науки и образования. - 2021. - № 3. ; URL: https://science-education.ru/ru/article/view?id=30771 (дата обращения: 12.12.2021). - Текст : электронный.

2. Афанасьев, А. Цифровизация образования, все минусы электронной школы. Что будет с детьми? / А. Афанасьев. - URL: https://vc.ru/flood/43800cifrovizaciya-obrazovaniya-vse-minusy-elektronnoy-shkolychto-budet-s-detmi (дата обращения: 12.12.2021). - Текст : электронный.

3. Дьякова, Е. А. Цифровизация образования как основа подготовки учителя XXI века: проблемы и решения / Е. А. Дьякова, Г. Г. Сечкарева. - Текст : электронный // Вестник Армавирского государственного педагогического университета. - 2019. - № 2. - C. 24-35. - URL: https://cyberleninka.ru/article/ n/tsifrovizatsiya-obrazovaniya-kak-osnova-podgotovki-uchitelya-xxi-veka-problemyi-resheniya/viewer (дата обращения: 12.12.2021). Текст : электронный.

4. Средства обучения в условиях цифровизации образования: учеб. пособие /А.М. Санько: Издательство Самарского университета,2020.-50с.

5. Цифровизация образования. - URL: http://press.tstu.ru/index.php/aktualnoe-intervyu/2345- tsifrovizatsiya-obrazovaniya (дата обращения: 25.04.2020). - Текст : электронный.

(C) М. М. Чомаева, 2021 